\title{
EDITORIAL
}

\section{HISTÓRIA DAS CIÊNCIAS HUMANAS E SOCIAIS}

\author{
History of the Humanities and social sciences \\ Historia de las Humanidades y las ciencias sociales
}

\author{
BERNARDO BORGES BUARQUE DE HOLLANDA ${ }^{\text {I* }}$ \\ JOÃO MARCELO EHLERT MAIA ${ }^{1 *}$ \\ YNAÊ LOPES DOS SANTOS ${ }^{1 *}$
}

EDITORES

$A_{\text {o escolhermos o tema "História das ciências humanas e sociais" para o número } 67 \text { da }}$ revista Estudos Históricos, sabíamos que receberíamos um volume considerável de boas contribuições, afinal se trata de um tema interdisciplinar e que dialoga com uma quantidade significativa de agendas de pesquisa de longa tradição na historiografia e nas ciências sociais brasileiras. De fato, foi difícil chegar à seleção final de artigos, mas os dez textos aqui publicados dão aos leitores um excelente panorama desse vasto campo.

0 número é aberto com uma colaboração original da professora australiana Raewyn Connell sobre a construção do cânone na sociologia e sua vinculação com as dinâmicas históricas do colonialismo e do eurocentrismo. Seu artigo "Canon and colonies: the global trajectory of sociology" é uma excelente porta de entrada para uma discussão global do tema proposto para este número.

A sociologia paulista é, por sua vez, objeto de alentada investigação original de William Santos, Luiz Jackson e Max Gimenes, que destrincham aproximações e tensões entre escolas e discípulos dessa conhecida tradição intelectual brasileira no texto "Roger Bastide, Antonio Candido e a tese interrompida sobre o cururu".

http://dx.doi.org/10.1590/S2178-14942019000200001

\footnotetext{
' Escola de Clências Sociais da Fundação Getulio Vargas (CPDOC/FGV) - Rio de Janeiro - Brasil.

*Professores da Escola de Ciências Sociais da Fundação Getulio Vargas (CPDOC/FGV) e Editores da Revista Estudos Históricos (bernardo.hollanda@fgv.br; joao.maia@fgv.br; ynae.santos@fgv.br) ORCID ID: https://orcid.org/0000-00017781-4684; https://orcid.org/0000-0002-3330-871X; https://orcid.org/0000-0002-9685-9041
} 
O questionamento da tradição eurocêntrica na historiografia das ciências humanas é tema para Marcelo Rosa, no seu texto "Sociologias indígenas ioruba: a África, o desconcerto e ontologias na sociologia contemporânea", que reconstrói o debate iniciado por Akinsola Akiwowo sobre as indigenous sociologies, a fim de evidenciar sua rentabilidade teórica para a sociologia contemporânea.

A relação entre colonialismo e sociologia também surge no trabalho dos colegas portugueses Frederico Ágoas e Cláudia Castelo, que refletem sobre as iniciativas portuguesas de cooperação científica na África em "Ciências sociais, diplomacia e colonialismo tardio: a participação portuguesa na Comissão de Cooperação Técnica na África Subsaariana (CCTA)".

A revista também selecionou textos que procuram repensar o legado de intérpretes clássicos do pensamento brasileiro. Lorenna Zem El-Dine revisita a fração "verde-amarelo" do modernismo paulista e suas conexões com o ensaísmo clássico brasileiro e latino-americano em "Ensaio e interpretação do Brasil no modernismo verde-amarelo (1926-1927)", enquanto José Szwaco e Ramon Araújo lançam um olhar cuidadoso sobre a trajetória do conceito de populismo na sociologia paulista e questionam paradigmas explicativos de inspiração bourdieusiana no artigo "Quando novos conceitos entraram em cena: história intelectual do 'populismo' e sua influência na gênese do debate brasileiro sobre movimentos sociais".

Por fim, Lidiane Rodrigues evidencia a força da análise sociologizante da vida intelectual em seu estudo a respeito dos modos de apropriação dos intérpretes do Brasil por parte dos acadêmicos marxistas, em artigo que tem por título "Amar um autor: os marxistas nas universidades brasileiras e os intérpretes do Brasil".

A história da historiografia comparece com os dois textos que fecham o volume. Aryana Costa questiona o apagamento da atuação universitária dos profissionais do Instituto Histórico e Geográfico de São Paulo no seu "Um regime de transição: o papel do IHGSP no curso de história da Universidade de São Paulo (1934)", enquanto Victor da Silva, em "History of the human sciences and Wallace's scientific voyage in the Amazon: notes on historiographical absences", reflete acerca das tensões entre história da ciência e outros campos historiográficos por meio de uma análise dos trabalhos que se debruçaram sobre a clássica viagem de Alfred R. Wallace pela Amazônia.

Acreditamos que este número da revista Estudos Históricos cumpra fielmente nossa vocação de apresentar conhecimento inovador e interdisciplinar sobre o Brasil e o exterior, apontando para a fertilidade de construirmos diálogos entre a história e as várias ciências sociais. Boa leitura!

\section{REFERÊNCIAS BIBLIOGRÁFICAS}

EL-DINE, Lorenna Ribeiro Zem. A alma e a forma do Brasil: o modernismo paulista em verde-amarelo (anos 1920). Tese (doutorado em história) - Programa de Pós-Graduação em História das Ciências e da Saúde, Casa de Oswaldo Cruz, Fundação Oswaldo Cruz, Rio de Janeiro, 2017.

ROSA, Marcelo C. Sociologies of the South and the actor-network-theory: possible convergences for an ontoformative sociology. European Journal of Social Theory, v. 19, n. 4, 2016. 